The Late Neandertal permanent lower left third premolar from Walou Cave (Trooz, Belgium) and its context

\title{
Authors' names and affiliations
}

Michel Toussaint ${ }^{1}$, Christine Verna ${ }^{2,3, *}$, Adeline Le Cabec ${ }^{3,4, *}$, Aida Gómez-Robles ${ }^{5}$, Christelle Draily $^{6}$, Michael P. Richards ${ }^{7,3}$, Stéphane Pirson ${ }^{6,8}$

* Both authors contributed equally

\section{${ }^{1}$ AWEM}

1 rue de l'Aumonier

4000 Liège, Belgium

mtoussaint1866@hotmail.com

${ }^{2}$ UMR 7194 CNRS/MNHN

Musée de l'Homme

Palais de Chaillot

17 Place du Trocadéro

75116 Paris Cedex 16, France

christine.verna@mnhn.fr

${ }^{3}$ Max Planck Institute for Evolutionary Anthropology

Department of Human Evolution

Deutscher Platz 6

D-04103 Leipzig, Germany

adeline_lecabec@eva.mpg.de

${ }^{4}$ ESRF - The European Synchrotron

71 avenue des Martyrs CS 40220

F-38043 Grenoble, Cédex 9, France

${ }^{5}$ Department of Anthropology

The George Washington University

Science and Engineering Hall

800 22nd St. NW Suite 6000

Washington, DC 20052, USA

aidagomezr@yahoo.es 
${ }^{6}$ Direction de l’Archéologie,

1 rue des Brigades d'Irlande

5100 Namur, Belgium

stephane.pirson@spw.wallonie.be

christelle.draily@spw.wallonie.be

${ }^{7}$ Department of Archaeology

Simon Fraser University

Burnaby, BC, Canada,V5A 1S6

michael_richards@sfu.ca

Number of text pages: 10 with in addition 5 pages of biblio

Number of figures: 4 (and 8 supplementary)

Number of tables: 3 (and 3 supplementary)

Abbreviated title

Walou Late Neandertal premolar

\section{Keywords}

Tooth, Mousterian, Neandertal, diet, MIS 3

\section{Corresponding author}

Dr. Michel Toussaint

AWEM

1 rue de l'Aumonier

4000 Liège, Belgium

e-mail: mtoussaint1866@hotmail.com

\section{Funding}

Service Public de Wallonie, Max Planck Society

\section{Abstract}

Objectives: We describe a hominin permanent lower left third premolar unearthed in 1997 at 
Walou Cave (Belgium), in association with Mousterian industries, in a layer confidently dated to 40-38,000 years BP.

Materials and Methods: The taxonomical attribution of the tooth is addressed through comparative morphometric analyses, and stable isotope analyses aim to depict the diet of the individual.

Results: The morphometric assessments of the Walou $\mathrm{P}_{3}$ plot within the Neandertal distribution and are significantly different from recent modern humans. The Walou individual acquired its dietary proteins from terrestrial food sources.

Discussion: We discuss the implications of the existence of a clearly Neandertal premolar dating to the Middle to Upper Paleolithic transition in the Meuse river basin.

In recent decades, research and debate have been devoted to the Middle to Upper Paleolithic transition (MUPT) in Western Eurasia, and to the Neandertal replacement by modern humans between 40,000 and 35,000 BP (e.g., Hublin, 2015; Richter, 2016). These topics involve related issues such as the possible chronological overlap and interbreeding between both groups, the existence of refuge areas for late Neandertals, the association between lithic technocomplexes and hominins (e.g., Green et al., 2010; Higham et al., 2014; Nigst et al., 2014; Fu et al., 2016).

Recently, interdisciplinary reassessment of the Spy and Goyet anthropological collections involving new direct AMS dating suggested a late survival of Neandertals in the Belgian Meuse Basin up to 36,000 BP (Toussaint and Pirson, 2006; Semal et al., 2009; see Table S1 for calibration of the dates). From an archeological perspective, the most recent Middle Paleolithic occupations of the area date back to 40-38,000 BP (Di Modica et al., 2016). The earliest reliable ages of the Belgian Aurignacian are around 33,500-32,000 BP (Flas, 2015). A possible transitional facies between the Middle Paleolithic and the Aurignacian has also been recognized as the Lincombian-RanisianJerzmanowician (LRJ; Flas, 2011). However, the relationship between material cultures and the Northwestern Europe hominin fossils is not always clear.

In this context, excavations at Walou Cave allowed the study of a sequence covering the Late Pleistocene, with several layers yielding archeological artifacts as well as a hominin premolar.

\section{Context of the Walou tooth}

Walou Cave (Trooz, Province of Liège, Belgium), in the Meuse River Basin (Fig. S1), is composed 
of a terrace and a narrow cave opening in Visean limestones. It was excavated twice: from 1985 to 1990 (Dewez, 2008), and from 1996 to 2004 (Draily, 2011).

The hominin tooth (WA97 G24-120) was found in 1997 in Layer CI-8. It was identified during the sorting of the paleontological collections. It had however been positioned in stratigraphy and in three dimensions during fieldwork (Fig. S1; Draily et al., 1999).

The stratigraphic sequence and paleoenvironment of Walou Cave. The local topography transformed Walou Cave into a sedimentary trap. It was possible, by integrating all the stratigraphic lateral variations, to reconstruct its sedimentogenesis and a synthetic sequence ( $\sim 12 \mathrm{~m})$, with 50 stratigraphic units distributed into 10 sedimentary cycles. Thirteen climatic improvements were identified across the sequence. Here we will only focus on Layer CI-8, where the tooth was found, as well as under- and overerlying units, respectively CII-1 and CI7/6 (Pirson et al., 2011; Fig. S2; Text SI 1).

Mettre en supplementary data, pas important ici

Chronostratigraphy. The sequence of Walou Cave ranges from the end of the Middle Pleistocene to the Holocene (Fig. S2; Pirson et al., 2011).

Cycle CI belongs to the Weichselian Middle Pleniglacial (MIS 3). The layer CII-1 , directly underlying CI-8, is a paleosol which might be equivalent to "Les Vaux" Soil. This correlation is fully compatible with the stratigraphic position of CII-1 at Walou and is reinforced by several dates framing Unit CII-1. It provides a terminus post-quem for the Neandertal tooth and the associated Middle Paleolithic material, which would therefore be younger than 40,000 BP (details in Text SI 2).

Lithic artifacts. Walou Cave yielded an important series of prehistoric lithic industries ranging from the Middle Paleolithic to the Upper Paleolithic and finally to the Mesolithic and Neolithic (Draily, 2011). Layer CI-8, where the hominin tooth comes from, yielded 1280 Mousterian flint artefacts (See detail in Text SI 3, Table S2 \& Fig. S3). The core reduction technique is essentially unifacial, unipolar and centripetal centered on an important production of backed pieces.

\section{Materials and methods}

The Walou tooth is a well preserved mandibular left third premolar $\left(\mathrm{P}_{3}\right)$, with a complete crown and a taphonomically broken root (apical third broken; Fig. 1). The Walou $\mathrm{P}_{3}$ is compared to samples of Neandertals, Middle Paleolithic early (MP-EMH), Upper Paleolithic (UP-MH) and recent (RMH) 
modern humans from historical periods (Table S3).

Seven morphological features of the occlusal surface were scored according to the ASUDA System (Turner et al., 1991) supplemented by Bailey (2002) and Martinón-Torres et al. (2012). The MD (mesio-distal) and BL (bucco-lingual) dental crown diameters of the Walou $\mathrm{P}_{3}$ are compared to the groups described above using univariate analyses (adjusted z-score; Azs) and bivariate graphs. The occlusal outline of the Walou premolar was also studied using a 2D geometric morphometric approach (Mitteroecker and Gunz, 2009; Gómez-Robles et al., 2008; Text SI 4).

The actual root length was measured on the lingual side of the tooth. Furthermore, an estimation of the missing portion of the root apical third was made on the $\mu \mathrm{CT}$ data (Text SI 5) for comparison with the data provided by Bailey (2005).

Finally, we undertook isotopic dietary analysis of collagen extracted from a dentine sample taken from the Walou tooth to determine the main sources of protein in the individual's diet (Texts SI 4 and $6)$.

\section{Results}

Morphological and metric description of the Walou $P_{3}$. The tooth is a permanent mandibular left $\mathrm{P}_{3}$ (Figs. 1, 2 and S 4) that likely belonged to an adult given its stage of occlusal wear.

[Figures 1 and 2 here]

Its crown has a bucco-lingual diameter of $9.3 \mathrm{~mm}$ and a mesio-distal diameter of $7.9 \mathrm{~mm}$ (Table 2). The bucco-lingual and mesio-distal diameters at the cervix are $8.1 \mathrm{~mm}$ and $5.6 \mathrm{~mm}$. The height of the crown, measured on the vestibular face, is $9.0 \mathrm{~mm}$, and $8.3 \mathrm{~mm}$ on the lingual face.

The premolar is two-cusped, without any accessory lingual cusplet (premolar lingual cusp variation ASUDAS 0). The crown is somewhat triangular in outline, the lingual half being smaller than the buccal.

The protoconid is heavily worn and shows an exposed dentine surface which draws a narrow and mesio-distally elongated triangular area (stage 3 after Molnar, 1971). The metaconid is by contrast almost unworn. In spite of the strong occlusal wear, the protoconid was much higher than the metaconid as it is generally the case in third mandibular premolars. Two interproximal wear facets 
are present on the mesial and distal faces of the crown and are slightly concave in occlusal view. The distal interproximal facet $(4.8 \mathrm{~mm} \times 3.3 \mathrm{~mm})$ exhibits five sub-vertical grooves, the three most buccal ones being deeper and longer. There is no groove on the mesial facet $(3.1 \mathrm{~mm} \times 3.4 \mathrm{~mm})$.

Two strong essential crests run from the protoconid and metaconid tips toward the center of the crown where they joined each other, forming a transverse crest that is continuous and not interrupted by the groove (grade 2 of Martinón-Torres et al., 2012). The crest is also present at the EDJ where it connects the base of the protoconid to the apex of the metaconid (Fig. S5). The mesial and distal foveae lie on both sides of this crest and are themselves limited by thick marginal crests. The mesial fovea forms a long bucco-lingual groove that does not extend on the lingual face of the crown (no mesio-lingual groove or MLG; grade 0 of Bailey, 2002; Table 1). From the distal fovea, two small grooves run along the lingual side of the buccal cusp, and limit a distal accessory ridge (grade 1 of Bailey, 2002; Martinón-Torres et al., 2012). This accessory crest is also well developed at the EDJ (Fig. S5). The buccal face of the crown is strongly convex, both vertically in lateral view and mesio-distally in occlusal view and bulges close to the cervix. The strong convexity of the buccal face of the protoconid, together with the location of the exposed dentine shows that the tip of the protoconid was projected lingually close to the metaconid. As a result, the occlusal polygon (see Gómez-Robles et al., 2008) was small and lingually placed. In addition, the metaconid is slightly distally displaced relative to the protoconid and the talonid is small. The mesial part of the lingual outline is longer than the distal part (estimating the part that is obscured by the interproximal facet) and shows a slight inflection at the level of the mesial fossa. All these features give the crown outline an asymmetric shape.

On both interproximal sides, the cervical line is more convex towards the occlusal plane, especially on the mesial side (Fig. 1).

The tooth has a single and broken root, which was likely completely formed, and approximately one third of it is currently missing (Figs. 1, 2, S4 and S35).The fracture is ancient and of taphonomic origin. The breakage follows an oblique plan that slopes buccally and distally from top to bottom. The root deflects distally and exhibits a rather flat mesio-distal section. There are two shallow mesial and distal developmental grooves (Fig. S6).

Comparative analyses and taxonomical attribution of the Walou $\boldsymbol{P}_{3}$. Four out of the seven morphological discrete traits scored on Walou correspond to a pattern that is more frequently observed in Neandertals and Pleistocene modern humans (MP-EMH + UP-MH) than among RMH (Table 1). These involve the presence of a distal accessory ridge (DAR) and a transverse crest 
(TRCR), an asymmetric occlusal outline (ASYM) and an absence of a mesial location of the metaconid (MET-MES). The combination of these features aligns Walou with the Pleistocene samples.

For three traits, Walou shows a configuration that is slightly more frequent in Pleistocene EMH than in Neandertals (absence of MAR, MLC and MLG; Text SI 4, Table 1). MAR is however found in all groups with rather low frequencies, even though it occurs more often in Neandertals than on Pleistocene modern humans according to Bailey (2006;23.5\% vs 10\%) but not according to MartinonTorres et al., 2012 (4.8\% vs 8.3\%). Its absence on Walou thus does not bring much indication regarding its taxonomy. Similarly, an absence of multiple lingual cusps is found in all Pleistocene groups at rather high frequencies, including Neandertals (79.4\% according to Bailey, 2006 and 54.5\% for Martinón-Torres et al., 2012).

The presence of a transverse crest, as seen on Walou, has also been observed on both Neandertals and Pleistocene modern humans at a very high frequency and does not discriminate the taxa (Table 1). The same is true for the presence of a distal accessory ridge according to Bailey (2002, 2006), whereas according to Martinón-Torres et al. (2012), this trait is much more frequent in Neandertals (90\%, $\mathrm{n}=$ 20) than in Pleistocene modern humans ( $47 \%, n=15)$.

Finally, the occlusal outline asymmetry, although frequent in all Pleistocene group, is the most discriminating trait, observed in $94 \%$ of the Neandertals, $75 \%$ of the MP-EMH and only 56\% of the UP-MH. For this particular trait, Walou aligns better with Neandertals.

[Table 1 here]

As for geometric morphometric analyses, the occlusal anatomy of the Walou $\mathrm{P}_{3}$ plots on the area of the morphospace occupied by other Neandertals in the shape PCA (Fig. 3a). This area, however, overlaps with part of the range of distribution of modern humans. When looking at size-shape space, however, both species are much more clearly separated, in part because Neandertal premolars are larger than modern human's, but also because of the shape changes associated with these differences in size (Fig. 3b). The shape PCA and the size-shape PCA show a change in the patterns of occlusal variation explained by PC1 and PC2, mostly because the changes associated with PC2 in the shape PCA are those that are associated with size variation in the size-shape PCA, and are then recovered by PC1 in the latter analysis. Regardless of these changes in the structure of the morphospace, Neandertal $\mathrm{P}_{3}$ s tend to have a reduced and lingually located occlusal polygon (the area enclosed by 
the lines connecting the four landmarks) and a slightly asymmetric configuration that contrasts with the larger occlusal polygon of modern human $\mathrm{P}_{3}$ s and their more symmetric shape (Gómez-Robles et al., 2008). The Neandertal features are clearly present in the premolar from Walou, which shows a reduced and lingually placed occlusal polygon and a general asymmetric shape. These features drive the classification of this premolar as a Neandertal with high probability when based on shape variation (92.4\% of probability to be classified as a Neandertal) and on size-shape variation (99.7\% of probability to be classified as Neandertal). Together, these results strongly support a Neandertal classification for this specimen.

[Figure 3 here]

[Table 2 here]

The adjusted z-scores associated with the dental crown measurements show that the MD diameter of Walou $(7.9 \mathrm{~mm})$ falls well within the Neandertal range of variation (Table 2, Fig. S7), very close to the average of early Neandertal (EN) and in the upper half of the range of variation of late Neandertals (LN). This diameter is also included in the variation of our MP-EMH and UP-MH samples, but remains high compared to the UP-MH average and range of variation. It is excluded from the RMH range. The BL diameter $(9.3 \mathrm{~mm})$ is high and falls in the upper half of the Neandertal and MP-EMH ranges. It is excluded from the UP-MH and RMH ranges. Overall, the BL diameter is rather high relative to the MD diameter when compared to EN and MP-EMH, and therefore the crown index falls in the upper half of their range of variation. This index is however very close to the LN and UP-MH mean, showing similar crown proportions to these late Pleistocene samples. The crown base area is high, close to the EN mean, in the upper half of the LN and MP-EMH ranges and excluded from the UP-MH and RMH ranges of variation. On the bivariate plot (Figs. 4 and S7), the Walou tooth falls well within the late Neandertal 95\% confidence ellipses, just outside that of UP-MH, and well outside the $\mathrm{RMH}$ range.

[Figure 4 here]

Although the root of the $\mathrm{Walou} \mathrm{P}_{3}$ is broken, its length has been measured on the lingual side of the original specimen: $11.2 \mathrm{~mm}$ (Table 3). The amount of missing root was estimated in two ways. First, based on its morphology and by comparison to a series of other Neandertal $\mathrm{P}_{3}$, the missing part of the Walou root was estimated on the real specimen to a minimum of $5 \mathrm{~mm}$, yielding a minimal length of $16.2 \mathrm{~mm}$, which falls close to the Neandertal mean but at the upper limit of the UPMH. Second, on $2 \mathrm{D}$ slices (from the conventional $\mu \mathrm{CT}$-scans) of the root in the labio-lingual and in the mesio-distal 
planes of section (Fig. S8), the missing root was estimated and drawn based on the angle of the walls of the pulp chamber and on the thickness of the dentine walls at the broken tip. This yields an average estimation of $7 \mathrm{~mm}$ of broken root, and thus a $17 \mathrm{~mm}$ total root length, which also falls closer to the Neandertal mean documented by Bailey (2005). These estimations provide a third additional indication that would move Walou closer to Neandertals than to UP-MH.

[Table 3]

Carbone and nitrogen isotope analysis. The collagen was not well preserved in the Walou $\mathrm{P}_{3}$ and we did not obtain any useable collagen in the $>30 \mathrm{kDa}$ fraction usually used for radiocarbon dating and isotope analysis. We then further ultrafiltered the smaller fraction and obtained collagen from in the 10 to $30 \mathrm{kDa}$ fraction that we were then able to measure the carbon and nitrogen isotopes from. This collagen fraction had a $\delta^{13} \mathrm{C}$ value of $-22.6 \%$ and a $\delta^{15} \mathrm{~N}$ value of $9.3 \%$. The extract had a $\mathrm{C}: \mathrm{N}$ ratio of 3.4 and a $\% \mathrm{C}$ value of $22.4 \%$ and a $\% \mathrm{~N}$ value of $7.6 \%$. The $>10 \mathrm{kDa}$ fraction was much more poorly preserved, and had a $\mathrm{C}: \mathrm{N}$ ratio of 4.5 which is outside of the acceptable range for collagen (DeNiro, 1985) so we did not include the isotope data from this fraction here.

The carbon isotope value of $-22.6 \%$ from the 10 to $30 \mathrm{kDa}$ fraction indicates that the specimen obtained most of its dietary protein from terrestrial food sources. Without contemporary faunal collagen nitrogen isotope data from Walou cave, we cannot definitively interpret the nitrogen isotope value. This is because the nitrogen isotope values of mammals (especially herbivores) do fluctuate over time (Richards and Hedges, 2003) so it is necessary to compare the Neanderthal value to contemporary fauna to use it to determine trophic position. However, the value of $9.3 \%$ obtained for Walou is similar to nitrogen isotope values of other contemporary Neandertals from Northern Europe (Richards and Trinkaus, 2009) as well as the Neandertal dredged from the North Sea just off the coast of Belgium (Hublin et al., 2009), which had $\delta^{15} \mathrm{~N}$ values of 10.1\%o (>30 kDa fraction) and $10.2 \%$ (10-30 kDa fraction). It is, however, quite different from the Neandertals from the sites of Goyet and Spy, Belgium (Wißing et al. 2016), which have higher $\delta^{15} \mathrm{~N}$ values ( 11\%o).

\section{Discussion}

The Walou premolar exhibits a combination of morphological features and metrics that align it with the Pleistocene samples and distinguish it from recent humans. The scored morphological features of 
its occlusal surface are compatible with both Neandertals and EMH. However, its overall topography, with a small and lingually displaced occlusal polygon and an asymmetric lingual outline, is typically not observed in modern human $\mathrm{P}_{3}$ s, but it is frequently shown by premolars within the Neandertal lineage. In addition, its dental metrics also position Walou among Neandertals. These results add to other evidence that Neandertals were still present in the Meuse Valley after 40,000 BP, producing Mousterian lithic artifacts.

The Belgian Meuse Basin is of high interest when studying the MUPT as well as the replacement of Neandertals by early modern humans. Firstly, this small area has yielded dozens of archeological sites from this period (Flas, 2015; Di Modica et al., 2016). Secondly, it is rich in hominin remains. In addition to Walou, seven other caves of the area yielded Pleistocene fossils, mostly Neandertals (Toussaint and Pirson, 2014). At least four of these seven sites can be related to Late Middle Paleolithic. Anatomically modern humans were also recently identified in the $19^{\text {th }}$ century collections from Goyet Cave and were dated from Aurignacian to Magdalenian (Posth et al., 2016). Thirdly, some of these sites have been the subject of recent interdisciplinary studies: Scladina, Walou, Couvin and Trou Al’Wesse in karstic environment (Bonjean et al., 2014; Draily, 2011; Miller et al., 2011), and Maisières-Canal and Veldwezelt-Hezerwater in open-air environments (Miller et al., 2004; Bringmans, 2006). In addition other sites excavated in the $19^{\text {th }}$ century have also recently benefited from new studies including AMS radiocarbon dates, such as for Spy and Goyet (Rougier and Semal, 2013; Rougier et al., 2016).

At the scale of the immediately neighboring regions, there are very few possible comparisons, as most of the sites that yielded Neandertal and UP-MH remains are older excavations without a reliable chronostratigraphic context.

When integrating all the available datasets, the following temporal pattern emerges in the Meuse Basin and surrounding areas, from 45,000 BP onwards. Before this time, several Middle Paleolithic sites are known (Text SI 7).

From 45,000 to 40,000 BP, Neandertal remains are represented in two caves from the Meuse Basin. The first is Couvin, where a Neandertal $\mathrm{dm}_{2}$ is associated with late Middle Paleolithic (Toussaint et al., 2010). The second site is Goyet, where the two oldest ${ }^{14} \mathrm{C}$-dated Neandertal fossils are situated around 41,000-40,000 BP (Wißing et al., 2016), but without precise archeological context.

From 40,000 to 36,000 BP, Neandertals are still represented in the Meuse Basin, notably by the Walou 
$\mathrm{P}_{3}$ and its associated late Mousterian assemblage. Six directly-dated Neandertal fossils from Goyet are also ranging from 40,000 to $37,000 \mathrm{BP}$ but there is uncertainty about the associated lithic industries: Mousterian and/or LRJ. About $100 \mathrm{~km}$ north-east of Walou, the Neandertals from Feldhofer cave are also dated to around 39-40,000 BP (Street et al., 2006); however it is not possible to certify that the Mousterian artifacts recently found in the site are associated with the Neandertal fossils.

Around 36,000 BP, Neandertals are still represented by two directly-dated individuals from Spy (Semal et al., 2009) and one from Goyet (Wißing et al., 2016). In both cases, the associated lithic industry is imprecise, LRJ, or very late Mousterian.

From 34,000 BP to ca 29,000 BP, the few regional archeological assemblages are attributed to the Aurignacian (Flas, 2015). However, a reliable chronostratigraphic data are lacking most of the time. Some radiocarbon dates are available for only three sites from the Belgian Meuse Basin: Spy (32,800 BP; Semal et al., 2009), Trou Al’Wesse (33,650 BP; Miller et al., 2011) and Goyet ( 30,000 BP; Posth et al., 2016).

About $100 \mathrm{~km}$ to the West, the open-air site of Maisières-Canal yielded an assemblage from recent Aurignacian with a reliable chronostratigraphy (Haesaerts, 2004). About $100 \mathrm{~km}$ to the East, the Rhineland site of Lommersum (Germany) provided an early Aurignacian occupation dated between 35,000 and 33,000 BP (Street et al., 2011). From an anthropological point of view, the only proven human fossils associated with that industrial facies in western Europe, mainly teeth, are anatomically modern humans (Churchill and Smith, 2000; Bailey et al., 2009; Verna et al., 2012). The direct dates recently obtained on human fossils from Goyet Cave support this hypothesis.

At about $450 \mathrm{~km}$ south of Walou, numerous Neandertal remains have been found at Arcy-sur-Cure (Burgundy, France). These fossils were mainly found in a Châtelperronian context but some teeth are from Mousterian layers (Leroi-Gourhan, 1958; Hublin et al., 2012). Even if there is disagreement among researchers about the Châtelperronian layers being mixed for some (Bar Yosef \& Bordes, 2010), the archaeological sequence seems now quite confidently dated and the association between Châtelperronian and Neandertals has been strengthened (Welker et al., 2016). Broadly, the data from Arcy-sur-Cure are compatible with the Mosan model: Late Mousterian before 40,000 BP, transitional industries (Châtelperronian) between 40,000 and 36,000 BP, early Upper Paleolithic (Proto Aurignacian) after 35,000 BP. 
In 1927, around $650 \mathrm{~km}$ west of Walou was found the Kent's Cavern 4 maxilla (United Kingdom). It is most often interpreted as modern, notably because its teeth possess more modern human than Neandertal characteristics (Keith, 1927). Its direct ${ }^{14} \mathrm{C}$ AMS date of 30,900 \pm 900 BP (OxA-1621) seems to be contaminated (Higham et al., 2011). According to AMS radiocarbon dates obtained using ultrafiltration on animal remains found above and below it, the maxilla has been reported as being much older, with a modelled age of 44,180-41,530 cal BP, i.e. $~ 40,000-37,000$ BP. This date has however been challenged because the sedimentary context was not well-controlled due to poorly executed excavations (White and Pettitt, 2012). Furthermore, such an ancient date for modern humans does not fit within the general pattern that emerges in the westernmost part of Europe (Hublin, 2015). However if such an antiquity was validated by new discoveries, this could change our model of the Meuse Basin. 


\section{LITERATURE CITED}

Bailey SE. 2002. Neandertal dental morphology: implications for modern human origins.

Bailey SE. 2005. Diagnostic dental differences between Neandertals and Upper Paleolithic modern humans: getting to the root of the matter. In: Zadzinska E, editor. Current Trends in Dental Morphology Research. Łódź (Poland): University of Łódź Press. p 201-210.

Bailey SE. 2006. Beyond shovel-shaped incisors: Neandertal dental morphology in a comparative context. Period Biol 108:253-267.

Bailey SE, Weaver TD, Hublin J-J. 2009. Who made the Aurignacian and other early Upper Paleolithic industries? J Hum Evol 57:11-26.

Bar-Yosef O, Bordes J-G. 2010. Who were the makers of the Châtelperronian culture? J Hum Evol 59:586-593.

Bonjean D, Abrams G, Di Modica K, Otte M, Pirson S, Toussaint M. 2014. Chapter 2 - Scladina Cave: archaeological context and history of the discoveries. In: Toussaint M, Bonjean D, editors. The Scladina I-4A Juvenile Neandertal (Andenne, Belgium), Palaeoanthropology and Context. ERAUL Editions. Andenne: Etudes et Recherches Archéologiques de l’Université de Liège. p 31-48.

Bringmans PM. 2006. Multiple Middle Palaeolithic occupations in a loess-soil sequence at Veldwezelt-Hezerwater Limburg, Belgium.

Churchill SE, Smith FH. 2000. Makers of the early Aurignacian of Europe. Am J Phys Anthropol 113:61-115.

DeNiro MJ. 1985. Postmortem preservation and alteration of in vivo bone collagen isotope ratios in relation to palaeodietary reconstruction. Nature 317:806-809.

Dewez M ed. 2008. Recherches à la grotte Walou à Trooz (Belgique). Second rapport de fouille. BAR International Series 1789.

Di Modica K, Toussaint M, Abrams G, Pirson S. 2016. The Middle Palaeolithic from Belgium: chronostratigraphy, territorial management and culture on a mosaic of contrasting environments. Quat Int 411, Part A:77-106.

Draily C. 2011. La grotte Walou à Trooz (Belgique). Fouilles de 1996 à 2004. Vol. 3 L’Archéologie. Etudes et documents - Archéologie 22. Namur.

Draily C, Yernaux G, Cordy JM, Toussaint M. 1999. Découverte d’une dent humaine dans une couche moustérienne de la grotte Walou à Trooz (fouille 1997). Notae Praehistoricae 19:29_ 
38.

Flas D. 2011. The Middle to Upper Paleolithic transition in Northern Europe: the LincombianRanisian-Jerzmanowician and the issue of acculturation of the last Neanderthals. World Archaeol 43:605-627.

Flas D. 2015. The chronocultural sequence of Belgian complexes in the European Aurignacian context. In: White R, Bourrillon R, editors. Aurignacian genius: art, technology and society of the first Modern Humans in Europe. Vol. 7. Proceedings of the International Symposium, April 08-10 2013. New York University. p 57-75.

Fu Q, Posth C, Hajdinjak M, Petr M, Mallick S et al. 2016. The genetic history of Ice Age Europe. Nature 534:200-205.

Gómez-Robles A, Martinón-Torres M, Bermúdez de Castro JM, Prado L, Sarmiento S, Arsuaga JL. 2008. Geometric morphometric analysis of the crown morphology of the lower first premolar of hominins, with special attention to Pleistocene Homo. J Hum Evol 55:627-638.

Green RE, Krause J, Briggs AW, Maricic T, Stenzel U at al. 2010. A draft sequence of the Neandertal genome. Science 328:710-722.

Haesaerts P. 2004. Maisières-Canal (2000-2002): cadre stratigraphique. In: Miller R, Haesaerts P, Otte M, editors. L’atelier de taille aurignacien de Maisieres-Canal (Belgique). Vol. 110. ERAUL. p 13-26.

Higham T, Compton T, Stringer C, Jacobi R, Shapiro B, Trinkaus E, Chandler B, Groning F, Collins C, Hillson S, O’Higgins P, FitzGerald C, Fagan M. 2011. The earliest evidence for anatomically modern humans in northwestern Europe. Nature 479:521-524.

Higham T, Douka K, Wood R, Ramsey CB, Brock F et al. 2014. The timing and spatiotemporal patterning of Neanderthal disappearance. Nature 512:306-309.

Hublin J-J. 2015. The modern human colonization of western Eurasia: when and where? Quat Sci Rev 118:194-210.

Hublin J-J, Talamo S, Julien M, David F, Connet N, Bodu P, Vandermeersch B, Richards MP. 2012. Radiocarbon dates from the Grotte du Renne and Saint-Césaire support a Neandertal origin for the Châtelperronian. Proc Natl Acad Sci 109:18743-18748.

Hublin JJ, Weston D, Gunz Ph, Richards MP, Roebroeks W, Glimmerveen J, Anthonis D. 2009. Out of the North Sea: the Zeeland Ridges Neandertal. J Hum Evol 57: 777-785.

Keith A. 1927. Report on a fragment of a human jaw found at a depth of (10 1/2 ft) $3.2 \mathrm{~m}$ in the cave earth of the vestibule of Kent’s Cavern. Trans Proc Torquay Nat Hist Soc 5:1-2. 
Le Cabec A, Tang NK, Tafforeau P. 2015. Accessing developmental information of fossil hominin teeth using new synchrotron microtomography-based visualization techniques of dental surfaces and interfaces. PLoS ONE 10:e0123019.

Leroi-Gourhan A. 1958. Etude des restes humains fossiles provenant des grottes d'Arcy-sur-Cure. Ann Paléontol 44:87-148.

Martinón-Torres M, Bermúdez de Castro JM, Gómez-Robles A, Prado-Simón L, Arsuaga JL. 2012. Morphological description and comparison of the dental remains from Atapuerca-Sima de los Huesos site (Spain). J Hum Evol 62:7-58.

Miller R, Collin F, Otte M, Stewart J. 2011. Le Trou Al’Wesse: du Moustérien au Néolithique dans la vallée du Hoyoux. In: Toussaint M, Di Modica K, Pirson S, editors. Le Paléolithique moyen en Belgique. Mélanges Marguerite Ulrix-Closset. Bulletin des Chercheurs de la Wallonie, ERAUL 128. p 335-342.

Miller R, Haesaerts P, Otte M. 2004. L’atelier de taille aurignacien de Maisières-Canal (Belgique). ERAUL 110.

Mitteroecker P, Gunz P. 2009. Advances in Geometric Morphometrics. Evol Biol 36:235-247.

Molnar S. 1971. Human tooth wear, tooth function and cultural variability. Am J Phys Anthropol 34:175-189.

Nigst PR, Haesaerts P, Damblon F, Frank-Fellner C, Mallol C, Viola B, Götzinger M, Niven L, Trnka G, Hublin J-J. 2014. Early modern human settlement of Europe north of the Alps occurred 43,500 years ago in a cold steppe-type environment. Proc Natl Acad Sci 111:14394-14399.

Pirson S, Draily C, Toussaint M eds. 2011. La grotte Walou à Trooz (Belgique). Fouilles de 1996 à 2004. Vol. 1 - Les sciences de la terre. Etudes et documents. Etudes et documents Archéologie 20. Namur.

Posth C, Renaud G, Mittnik A, Drucker DG, Rougier H et al. 2016. Pleistocene mitochondrial genomes suggest a single major dispersal of non-Africans and a late glacial population turnover in Europe. Curr Biol 26:827-833.

Richards MP, Hedges REM. 2003. Variations in bone collagen $\delta 13 \mathrm{C}$ and $\delta 15 \mathrm{~N}$ values of fauna from Northwest Europe over the last 40000 years. Palaeogeogr Palaeoclimatol Palaeoecol 193:261-267.

Richards MP, Trinkaus E. 2009. Isotopic evidence for the diets of European Neanderthals and early modern humans. Proc Natl Acad Sci 106:16034-16039. 
Richter J. 2016. Leave at the height of the party: A critical review of the Middle Paleolithic in Western Central Europe from its beginnings to its rapid decline. Quat Int 411, Part A:107128.

Rougier H, Crevecoeur I, Beauval C, Posth C, Flas D, Wißing C, Furtwängler A, Germonpré M, Gómez-Olivencia A, Semal P, van der Plicht J, Bocherens H, Krause J. 2016. Neandertal cannibalism and Neandertal bones used as tools in Northern Europe. Sci Rep 6:29005.

Rougier H, Semal P eds. 2013. Spy Cave. 125 years of multidisciplinary research at the Betche aux Rotches (Jemeppe-sur-Sambre, Province of Namur, Belgium). Anthropologica et Praehistorica 123.

Semal P, Rougier H, Crevecoeur I, Jungels C, Flas D, Hauzeur A, Maureille B, Germonpré M, Bocherens H, Pirson S, Cammaert L, De Clerck N, Hambucken A, Higham T, Toussaint M, van der Plicht J. 2009. New data on the late Neandertals: Direct dating of the Belgian Spy fossils. Am J Phys Anthropol 138:421-428.

Street M, Jöris O, Higham T, Löhr H. 2011. New Oxford AMS dates from the northern boundary of the Aurigancian oikumene. Presentation at the Hugo Obermaier Society, 53 Annual Sympsium. 26-30 April 2011, Herne, Germany.

Street M, Terberger T, Orschiedt J. 2006. A critical review of the German Paleolithic hominin record. J Hum Evol 51:551-579.

Toussaint M, Pirson S. 2006. Neandertal Studies in Belgium: 2000-2005. Period Biol 108:373-387.

Toussaint M, Pirson S. 2014. Chapter 20 - Scladina I-4A in the chronological context of the Neandertals from the Belgian Meuse valley and Northwest Europe. In: Toussaint M, Bonjean D, editors. The Scladina I-4A Juvenile Neandertal (Andenne, Belgium), Palaeoanthropology and Context. ERAUL Editions. Andenne: Etudes et Recherches Archéologiques de l’Université de Liège 134. p 395-408.

Toussaint M, Olejniczak AJ, El Zaatari S, Cattelain P, Flas D, Letourneux C, Pirson S. 2010. The Neandertal lower right deciduous second molar from Trou de l’Abîme at Couvin, Belgium. J Hum Evol 58:56-67.

Turner CGI, Nichol CR, Scott GR. 1991. Scoring procedures for key morphological traits of the permanent dentition: the Arizona State University dental anthropology system. In: Kelley M, Larsen CS, editors. Advances in Dental Anthropology. Vol. 13. New York: Wiley Liss. p 13-31.

Verna C, Dujardin V, Trinkaus E. 2012. The Early Aurignacian human remains from La Quina- 
Aval (France). J Hum Evol 62:605-617.

Welker F, Hajdinjak M, Talamo S, Jaouen K, Dannemann M, David F, Julien M, Meyer M, Kelso J, Barnes I, Brace S, Kamminga P, Fischer R, Kessler BM, Stewart JR, Pääbo S, Collins MJ, Hublin J-J. 2016. Palaeoproteomic evidence identifies archaic hominins associated with the Châtelperronian at the Grotte du Renne. Proc Natl Acad Sci 113:11162-11167.

White M, Pettitt P. 2012. Ancient Digs and Modern Myths: The Age and Context of the Kent's Cavern 4 Maxilla and the Earliest Homo sapiens Specimens in Europe. Eur J Archaeol $15: 392-420$.

Wißing C, Rougier H, Crevecoeur I, Germonpré M, Naito YI, Semal P, Bocherens H. 2016. Isotopic evidence for dietary ecology of late Neandertals in North-Western Europe. Quat Int 411, Part A:327-345. 


\section{FIGURE CAPTIONS}

Figure 1. The Walou left inferior third premolar: 1. Photographs and 3D models; 2. Details of the occlusal surface; 3. Close-up on a wear facet of the Walou distal interproximal facet.

Figure 2. Outer enamel surface of the Walou $\mathrm{P}_{3}$ rendered from synchrotron micro-CT scans (technical details in Text SI 3) using the protocol (normalized gradients, colored second light source oriented from the top) described in Le Cabec et al. (2015). Note the minute marks left by the laser ablation sampling (close-up framed in mesial view) on the enamel cap and the dentine root surface, as well as the more important trace of ${ }^{14} \mathrm{C}$ sampling (apical view).

Figure 3. Shape PCA (a) and size-shape PCA (b) of Neandertal and modern human $\mathrm{P}_{3}$ s showing the location of Walou premolar. TPS-grids show the patterns of variation corresponding to the positive and negative extreme of each principal component. Although analyses are based on right premolars, TPS-grids are mirror-imaged to facilitate comparisons with Walou, which is a left antimere and was in turn mirror-imaged for the purposes of these analyses. NE: Neandertals; FSAP: fossil modern humans (MP-EMH + UP-MH); RMH: recent modern humans.

Figure 4. Walou Cave, first lower left premolar, morphometric comparisons: relation between the mesio-distal and bucco-lingual diameters of different human $\mathrm{P}_{3} \mathrm{~S}$, with equiprobable ellipses at 95 \%, of recent Neandertals, Middle Paleolithic modern humans from Qafzeh and Skhul, Upper Paleolithic Homo sapiens and recent modern humans.

\section{TABLE TITLES}

Table 1. Morphological features of the occlusal surface scored for Walou and comparisons following the ASUDAS System. UP-MH = Upper Paleolithic - Modern Humans; MP-EMH = Middle Paleolithic/Middle Stone Age - Early Modern Humans; RMH = recent modern Humans.

Table 2. Statistical comparisons of the crown metrics in the Walou premolar and comparative groups: LN = late Neandertals (MIS 5d-3), EN = early Neandertals (MIS 7-5e), MP-EMH = Middle Paleolithic/Middle Stone Age Early modern humans, UP-MH= Upper Paleolithic modern humans (Aurignacian. Gravettian), RMH = recent modern humans (historical periods). MD = mesio-distal $(\mathrm{mm})$; BL = bucco-lingual $(\mathrm{mm}), \mathrm{IND}=$ crown index $(\mathrm{BL} \times 100 / \mathrm{MD}), \mathrm{CBA}=$ crown base area $=$ $\mathrm{BL} \times \mathrm{MD}$. Azs $=$ adjusted $\mathrm{z}$-score. Azs close to 0 means that Walou is close to the mean of the 
reference sample, while if $>1$ or $<-1$ Walou stands out of their variation.

Table 3. Root length of the Walou $\mathrm{P}_{3}$ and comparisons. 
Table 1

\begin{tabular}{lcccccc}
\hline & Walou Late Neand. & Azs Early Neand. & Azs MP-EMH & Azs UP-EMH & Azs Recent MH & Azs \\
\hline MD & $\mathbf{7 . 8 9} 7.6 \pm 0.4(28)$ & $0.337 .9 \pm 0.7(18)$ & $-0.018 .0 \pm 0.5(8)$ & $-0.137 .06 \pm 0.5(22)$ & $0.815,6 \pm 0,4(82)$ & $\underline{\mathbf{2 , 7 3}}$ \\
BL & $\mathbf{9 . 3 1} 8.9 \pm 0.7(28)$ & $0.289 .0 \pm 0.7(17)$ & $0.218 .9 \pm 0.6(9)$ & $0.318 .30 \pm 0.4(22)$ & $\underline{\mathbf{1 . 2 6}} 6,2 \pm 0,5(82)$ & $\underline{\mathbf{3 , 2 5}}$ \\
IND & $\mathbf{1 1 8 . 0 1} 117 \pm 8.5(28)$ & $0.06115 .3 \pm 6.6(17)$ & $0.19112 .9 \pm 7.1(8)$ & $0.30118 .3 \pm 6.3(20)$ & $-0.02111,6 \pm 6,7(82)$ & 0,48 \\
CBA & $\mathbf{7 3 . 3 7} 68.5 \pm 7.4(28)$ & $0.3271 .6 \pm 11.4(17)$ & $0.0772 .9 \pm 6.3(8)$ & $0.0359 .17 \pm 5.9(20)$ & $\underline{\mathbf{1 . 1 5}} 48,3 \pm 5,5(82)$ & $\underline{\mathbf{2 , 2 9}}$ \\
\hline
\end{tabular}

$\mathrm{MD}=$ mesio-distal $(\mathrm{mm})$

$\mathrm{BL}=$ bucco-lingual $(\mathrm{mm})$

$\mathrm{IND}=$ crown index $(\mathrm{BL} * 100 / \mathrm{MD})$

$\mathrm{CBA}=$ crown base area $=\mathrm{BL} * \mathrm{MD}$

$\mathrm{LN}=$ late Neandertals (OIS 5d-3)

$\mathrm{EN}=$ early Neandertals (OIS 7-5e)

MPMH = Middle Paleolithic modern humans (Qafzeh/Skhul)

EMUPMH = early and mid-Upper Pal modern humans (Aurignacian. Gravettian)

AZS = adjusted z-score. $\mathrm{Si}>1$ ou $<-1=$ hors variation 
Table 2

\begin{tabular}{lcrrrrrr}
\hline & MAR & \multicolumn{1}{c}{ DAR } & \multicolumn{1}{c}{ MLC } & MET-MES & \multicolumn{1}{c}{ TRCR } & \multicolumn{1}{c}{ ASYM } & \multicolumn{1}{c}{ MLG } \\
\hline Neandertals & $23.5(17)$ & $90.0(20)$ & $20.6(34)$ & $6.3(32)$ & $96.7(30)$ & $94.4(18)$ & $64.0(25)$ \\
UP-EMH & $12.5(08)$ & $100.0(09)$ & $7.1(14)$ & $20.0(15)$ & $81.3(16)$ & $56.3(16)$ & $50.0(14)$ \\
MP-EMH & $0(02)$ & $50.0(02)$ & $16.7(06)$ & $50.0(04)$ & $75.0(04)$ & $75.0(04)$ & $25.0(04)$ \\
RMH & $9.5(130)$ & $50.8(118)$ & $30.4(138)$ & \multicolumn{1}{c}{$35.7(140)$} & $68.1(137)$ & $7.5(120)$ & $38.5(127)$ \\
Walou & Abs & \multicolumn{1}{c}{ Pres } & \multicolumn{1}{c}{ Abs } & \multicolumn{1}{c}{ Abs } & Pres & Pres & Abs \\
\hline
\end{tabular}


Table 3

\begin{tabular}{|c|c|c|c|c|}
\hline $\begin{array}{l}\text { Actual root length of } \\
\text { the Walou P3 } \\
\text { (=broken) }\end{array}$ & 11.2 & & & \\
\hline $\begin{array}{l}\text { Attempt of } \\
\text { reconstruction: } \\
\text { BL } \\
\text { MD }\end{array}$ & $\begin{array}{l}\text { Existing } \\
\text { RL } \\
9.5 \\
10.6\end{array}$ & $\begin{array}{l}\text { Estimated } \\
\text { missing RL } \\
7.3 \\
6.4\end{array}$ & $\begin{array}{l}\text { Reconstructed } \\
\text { RL } \\
16.8 \\
17.0\end{array}$ & $\begin{array}{l}\text { Estimation from the } \mathrm{mCT} \\
\text { slices recorded in the } \mathrm{BL} \\
\text { and } \mathrm{MD} \text { planes of section }\end{array}$ \\
\hline $\begin{array}{l}\text { Comparative samples } \\
\text { Neandertals (7) } \\
\text { UP humans (6) }\end{array}$ & $\begin{array}{l}\text { Mean } \\
16.6 \\
13.6 \\
\end{array}$ & $\begin{array}{l}\text { Min-Max } \\
14.5-18.1 \\
11.4-16.3 \\
\end{array}$ & $\begin{array}{l}\text { SD } \\
1.11 \\
1.8\end{array}$ & \\
\hline $\begin{array}{l}\text { Azs } \\
\text { Walou BL } \\
\text { Walou MD }\end{array}$ & $\begin{array}{l}\text { Neandertals } \\
-0.09 \\
-0.19\end{array}$ & $\begin{array}{l}\text { UP humans } \\
-0.85 \\
-0.91\end{array}$ & & \\
\hline
\end{tabular}


Figure 1
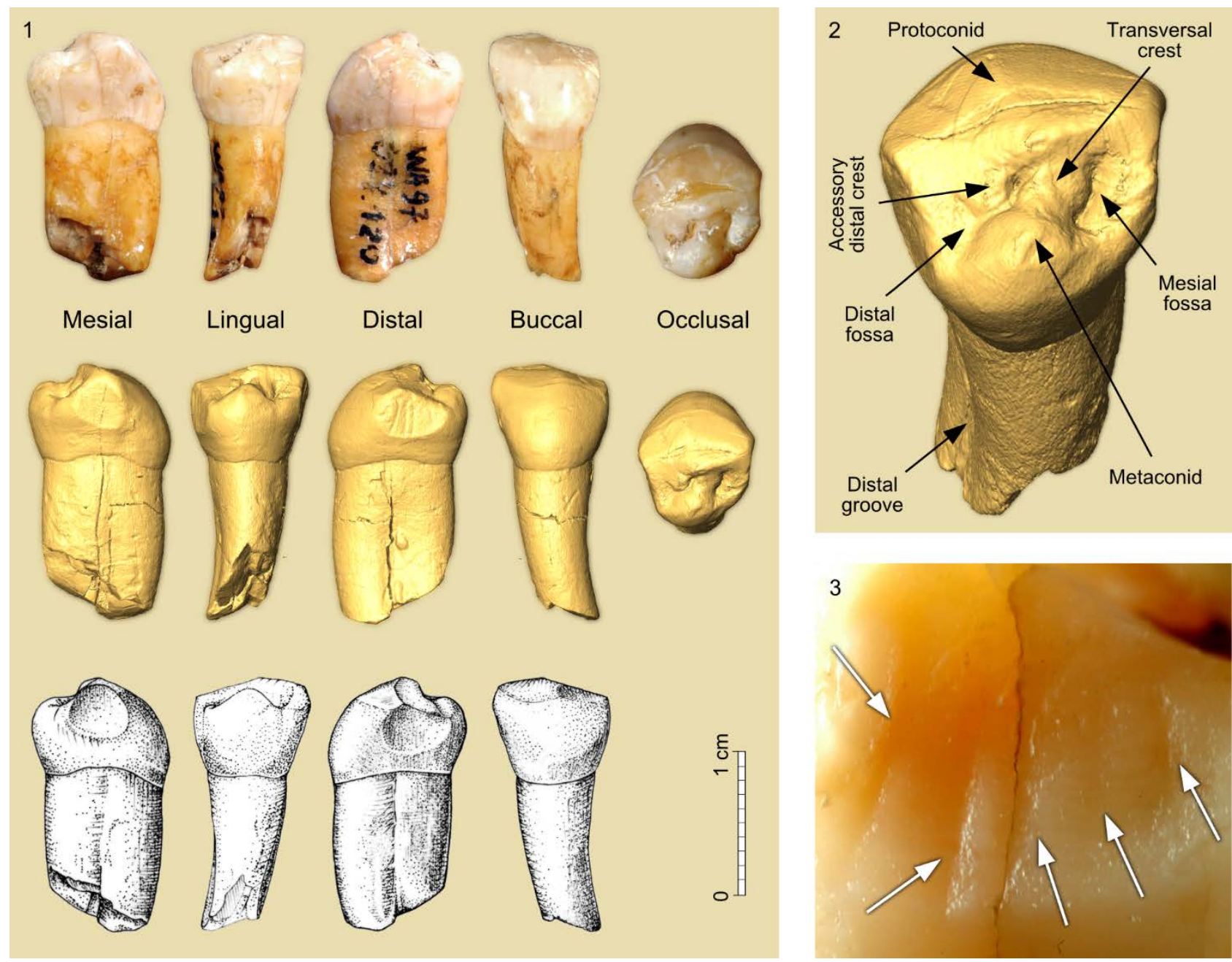

3

3

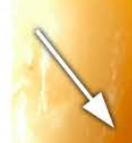


Figure 2

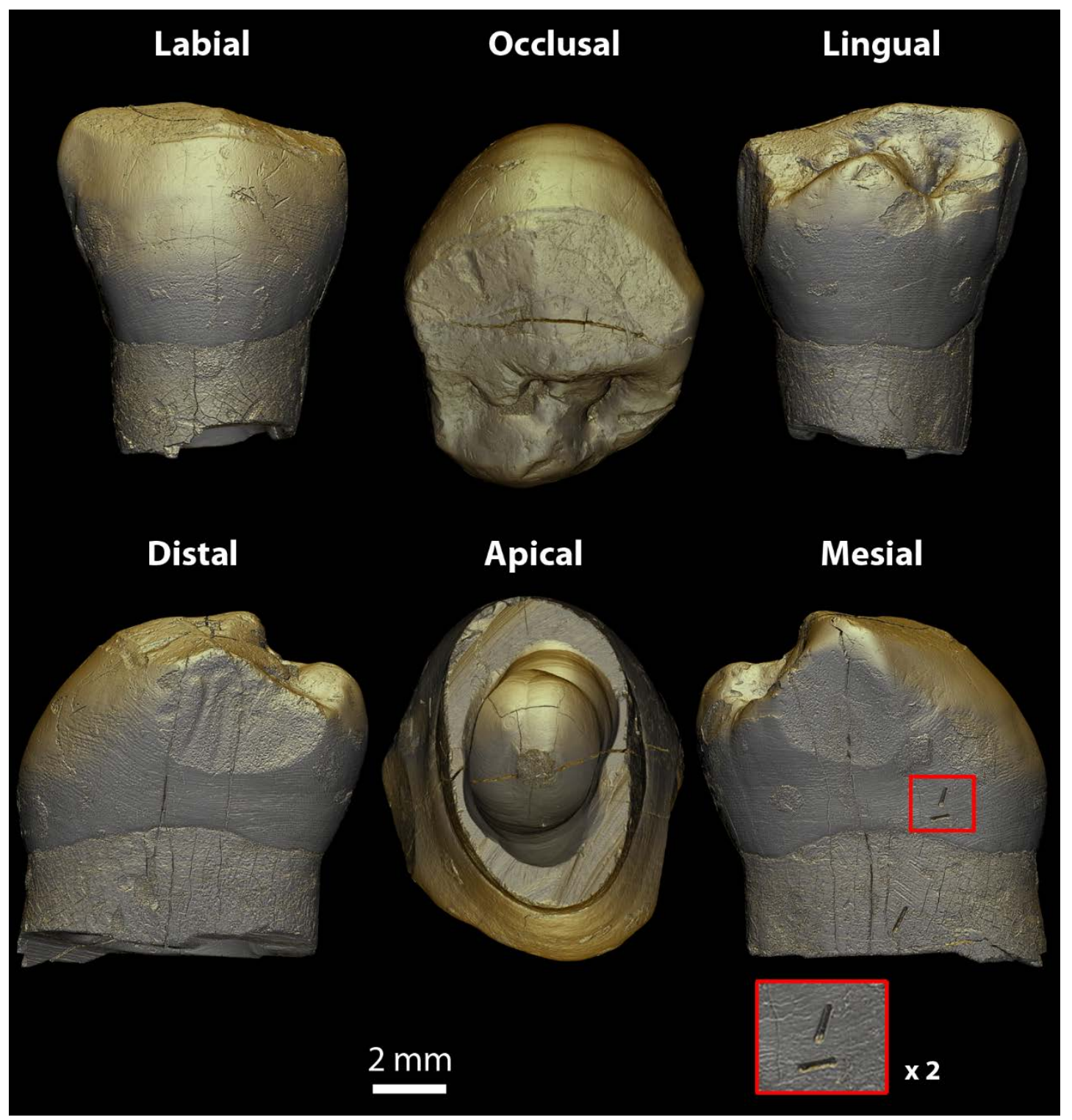



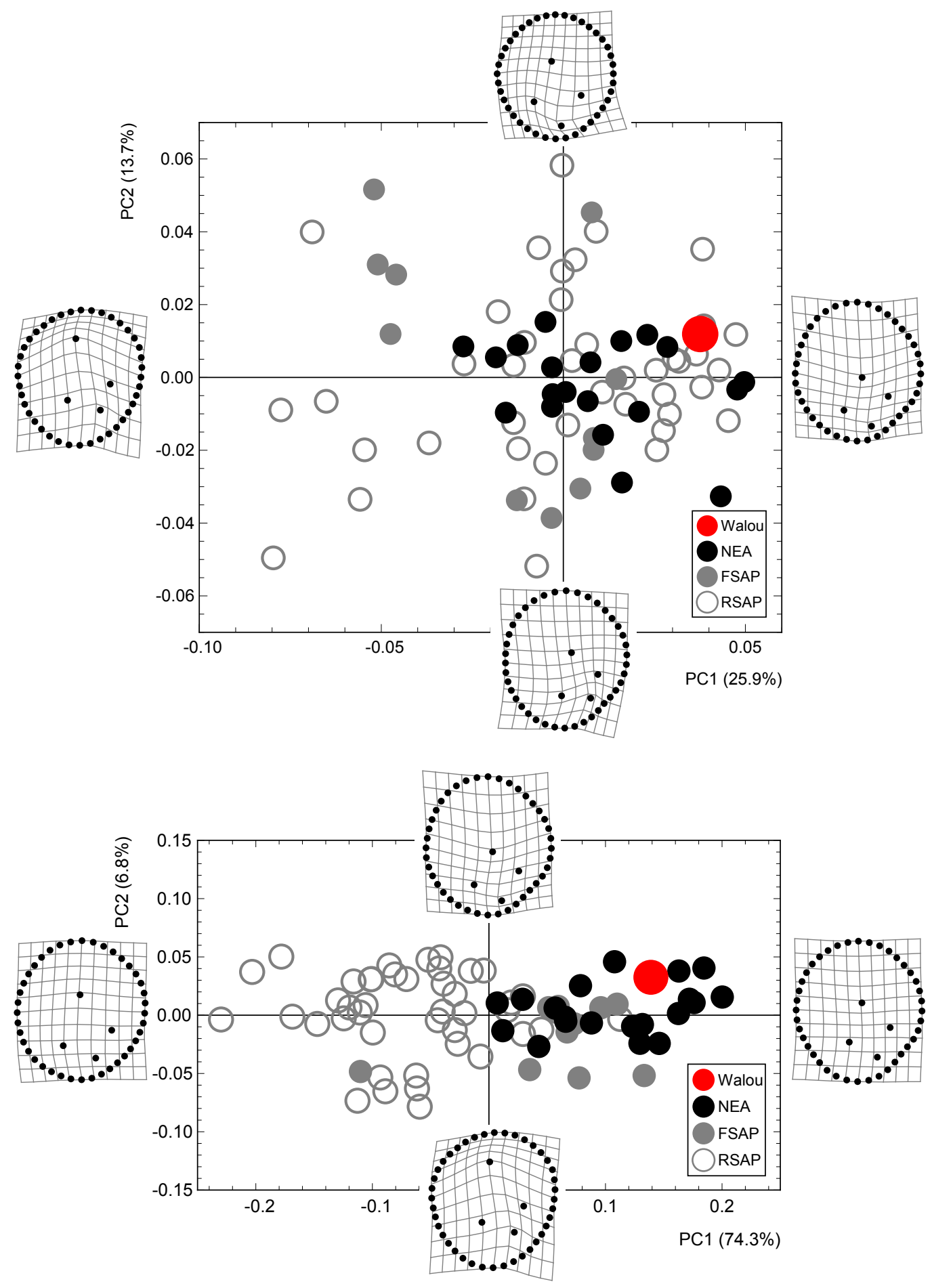
Figure 4

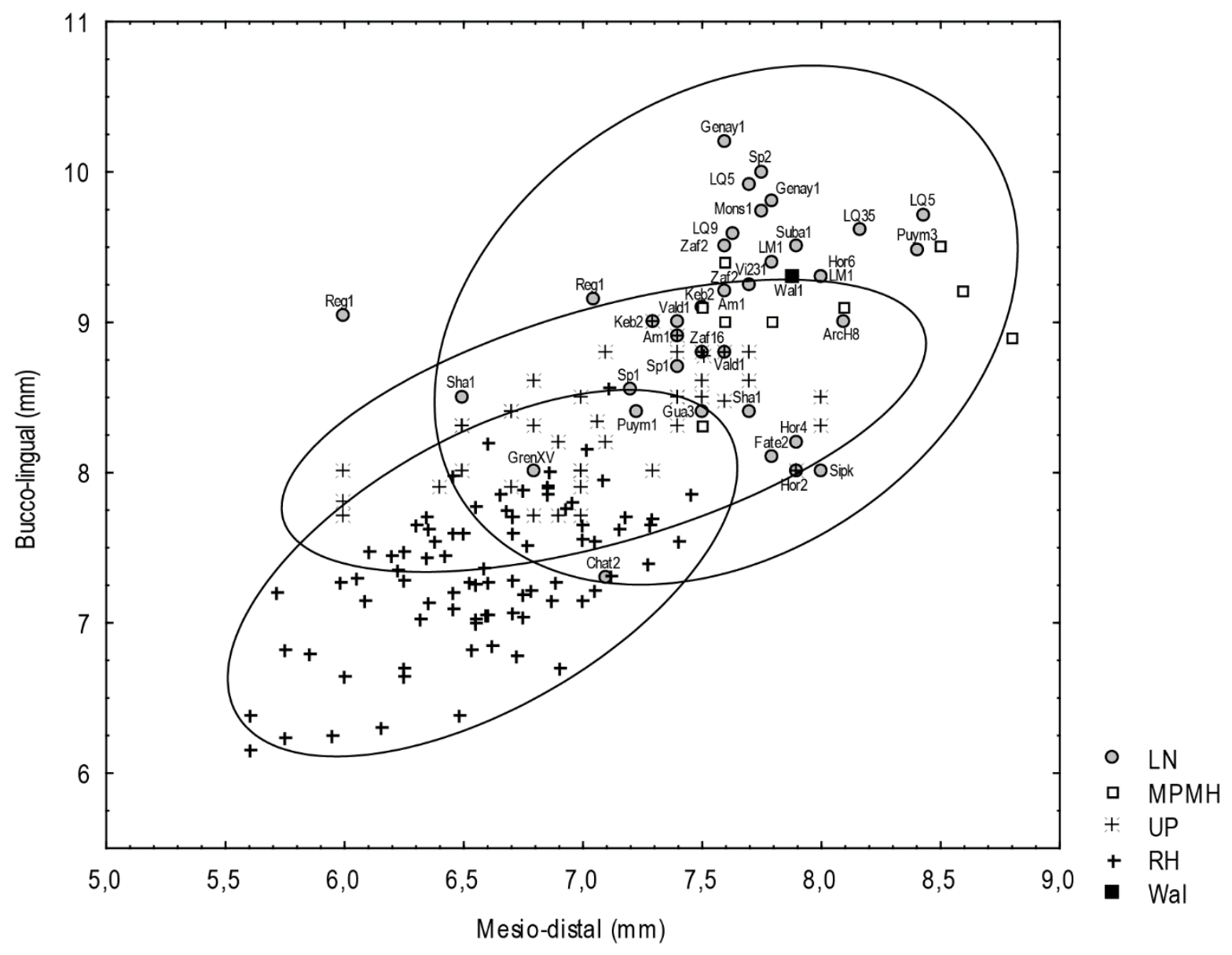

